\title{
Farklı düzeylerdeki sulama uygulamalarının kinoa bitkisi üzerine etkileri I: Bitki su tüketimi ve bitki katsayıları
}

\section{The effects of different levels of irrigation practices on quinoa I: Evapotranspiration and crop coefficients}

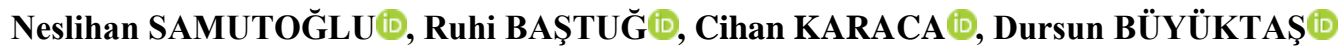 \\ Akdeniz Üniversitesi, Ziraat Fakültesi, Tarımsal Yapılar ve Sulama Bölümü, Antalya, Türkiye \\ Sorumlu yazar (Corresponding author): R. Baştuğ, e-posta (e-mail): rbastug@akdeniz.edu.tr \\ Yazar(lar) e-posta (Author e-mail): neslihansamutoglu@gmail.com, cihankaraca@akdeniz.edu.tr, dbuyuktas@akdeniz.edu.tr
}

\section{MAKALE BİLGİSİ}

Alınış tarihi 07 Mayıs 2020

Düzeltilme tarihi 21 Eylül 2020

Kabul tarihi 28 Eylül 2020

\section{Anahtar Kelimeler:}

Su verimliliği

Kisintıli sulama

Verim tepki etmeni

\section{ÖZ}

Bu çalışmada, Akdeniz iklim koşullarında yetiştirilen kinoanın su-verim ilişsileri, bitki su tüketimi ve bitki katsayılarının $\left(\mathrm{K}_{\mathrm{c}}\right)$ belirlenmesi amaçlanmıştır. Araştırma drenaj tipi lizimetre sisteminde, kumlu tın bünyeli toprakta, 2017 y1lında, Titicaca (Q-52) kinoa (Chenopodium quinoa Willd.) çeşidinde yürütülmüştür. Araştırmada tam sulama (TS), sırasıyla \%75, 50 ve 25 oranında kisintılı sulama (KS75, KS50, KS25), ve susuz (SZ) konuları tesadüf bloklar1 deneme deseninde üç tekerrürlü olarak ele alınmıştır. TS konusuna 7 günde bir toprak su içeriğini tarla kapasitesine getirecek kadar, kısıntılı sulama konularına ise belirtilen kısıntı oranları dikkate alınarak sulama suyu uygulanmıştır. $\mathrm{K}_{\mathrm{c}}$, TS konusundaki bitki su tüketimi (ET) ve FAO56-Penman-Monteith yöntemiyle hesaplanan kıyas bitki su tüketimi (ETo kullanılarak belirlenmiștir. ET değerleri 302.0 (TS) ile $198.2 \mathrm{~mm}$ (SZ), kinoa dane verimi ise aynı konularda sırasıyla 295.2 ve $243.0 \mathrm{~kg} \mathrm{da}^{-1}$ arasında değişmiştir. Kısıntılı sulama konularında TS konusuna göre kinoa dane veriminde istatistiksel olarak önemli azalmalar saptanmıştır. Antalya koşullarında, 15 Mart'ta ekilen kinoa bitkisinin başlangıç, gelişim, mevsim ortası ve olgunlaşma dönemleri sırasıyla 31, 36, 15 ve 26 gün, toplam gelişme dönemi 108 gün ve başlangiç, orta ve geç gelişim dönemleri için $\mathrm{K}_{\mathrm{c}}$, sirasiyla, $0.54,1.13$ ve 0.79 olarak saptanmıştır. Ayrıca, mevsimlik bitki verim tepki etmeni $\left(\mathrm{k}_{\mathrm{y}}\right) 0.54$ olarak belirlenmiştir.

\section{ARTICLE INFO}

Received 07 May 2020

Received in revised form 21 September 2020 Accepted 28 September 2020

\section{Keywords:}

Water productivity

Deficit irrigation

Yield response factor

\begin{abstract}
In this study, the water-yield relationships, evapotranspiration and crop coefficients $\left(\mathrm{K}_{\mathrm{c}}\right)$ of quinoa grown in Mediterranean climate conditions was determined. The research was conducted in drainage-type lysimeters, filled with sandy loam soil, in 2017 using Titicaca (Q52) quinoa (Chenopodium quinoa Willd.). Full (TS), 75\%, 50\%, 25\% of deficit irrigation (KS75, KS50, KS25) and rainfed (SZ) treatments were tested in randomized blocks design with three replications. Irrigation was applied to the TS treatment 7-day interval to bring the soil water content to the field capacity, and the deficit irrigation treatments were irrigated taking into account the specified cut-off rates. $K_{c}$ was determined using ET in TS and reference crop evapotranspiration $\left(\mathrm{ET}_{\mathrm{o}}\right)$ calculated by FAO56-Penman-Monteith. ET ranged from 302.0 (TS) to $198.2 \mathrm{~mm}$ (SZ), while grain yield ranged from 295.2 to $243.0 \mathrm{~kg} \mathrm{da}^{-1}$, respectively. Significant decrease in quinoa grain yield observed in deficit irrigation compared to TS. In Antalya conditions, the initial, development, mid- and late-season stages of the quinoa, planted in March 15, was 31,36, 15 and 26, respectively, and the total growing period was 108 days. $\mathrm{K}_{\mathrm{c}}$ was $0.54,1.13$ and 0.79 , respectively, for the initial, mid- and late-season stages. Additionally, seasonal yield response factor $\left(\mathrm{k}_{\mathrm{y}}\right)$ was 0.54 .
\end{abstract}




\section{Giriş}

Kinoa (Chenopodium quinoa Willd.), kuraklığa (Jacobsen ve ark. 2012), tuzlu koşullara (Talebnejad ve Sepaskhah 2015) ve düşük sıcaklıklara (Jacobsen ve ark. 2007) dayanımı yüksek olan, besin içeriği ve ekonomik değeri ile marjinal tarım alanları için alternatif olarak önerilebilecek (Jacobsen ve ark. 2006) bir bitkidir. Anavatanı Güney Amerika kıtasında asırlardır tarımı yapılan kinoa, dünyada geleceğin gıda ve yem bitkisi olarak ilgi çekmektedir (Jacobsen ve Stolen 1993; Schlick ve Bubenheim 1996). Vitamin, mineral ve antioksidan maddelerce zengin, protein içeriği ve kalitesi diğer tahıllara göre daha yüksek olan kinoa, insan beslenmesi açısından önemli bir gida maddesi (Koziol 1992) olup, kinoanın tohum kabuğunda bulunan saponin sabun, deterjan, șampuan, kozmetik ürün ve tıbbi ilaç yapımında kullanılır (Schlick ve Bubenheim 1996).

Çeşide ve iklimsel koşullara bağlı olarak kinoa bitkisinin gelişme mevsimi uzunluğu 90-180 gün arasında değişmektedir (Jacobsen 2003). Kinoanın Titicaca çeşidinin, Akdeniz iklimi koşullarına iyi adapte olabildiği bildirilmiştir (Lavini ve ark. 2014). Yazar ve Kaya (2014), Türkiye'de kinoa için en uygun ekim döneminin deniz seviyesinde yakın bölgelerde mart-nisan, yüksek bölgelerde ise nisan-mayıs ayları olduğunu açıklamışlardır.

Sınırlı su kaynaklarının sürdürülebilir kullanımı ve uygun sulama programlarının oluşturulmasında yöresel olarak belirlenen bitki su tüketimi (ET) ve bitki katsayısı $\left(\mathrm{K}_{\mathrm{c}}\right)$ değerleri temel verilerdendir. Pratikteki bir çok durumda bitki su tüketimi $\mathrm{ET}=\mathrm{K}_{\mathrm{c}} \times \mathrm{ET}_{\mathrm{o}}$ (burada $\mathrm{K}_{\mathrm{c}}=$ bitki katsayıs1, $\mathrm{ET}_{\mathrm{o}}=$ kıyas bitki-çimsu tüketimidir) ilişkisi kullanılarak FAO-56 yayınında yer alan yöntem yardımıyla tahmin edilebilir (Allen ve ark. 1998). Bunun için denemelerle, farklı yetiştirme koşulları ve gelişme dönemlerine ilişsin $\mathrm{ET}$ ve $\mathrm{ET}_{\mathrm{o}}$ arasındaki orandan belirlenmiş $\mathrm{K}_{\mathrm{c}}$ değerlerine gereksinim vardır. ET'nin denemelerle belirlenmesinde kullanılan yöntemlerden biri lizimetre yöntemidir. $\mathrm{ET}_{0}$ ise birçok yöntem ile hesaplanabilmektedir. Kısıntılı sulama işletmeciliği koşullarında bitkisel verim ve su kullanımı arasındaki ilişkiyi analiz için modellere gereksinim vardır. Stewart ve ark. (1977) tarafindan bildirilen model, oransal bitki su tüketimi açığı ile oransal verim azalması arasındaki etkileri bir verim tepki etmeni (ky) ile açıklama olanağ 1 verir.

Kinoada verim, sulamadan önemli ölçüde etkilenir (Flynn 1990). Geerts ve ark. (2008), Bolivya'da yapilan lizimetre denemelerinde tam sulamanın yarısı kadar sulamayla 1200-2000 $\mathrm{kg} \mathrm{ha}^{-1}$ arasında kararlı bir kinoa verimi sağlanabileceği sonucuna varmışlardır. İran'da, deniz seviyesinden $1810 \mathrm{~m}$ yükseklikte, sera koşullarında yürütülen bir çalışmada, kısıntılı sulamanın kinoanın verim unsurlarına etkileri araştırılmış, tam sulamaya göre $\% 70$ azaltılmış sulama suyu uygulamasında tohum veriminin maksimuma göre $\% 36$ azaldığ tohum verimine dayalı su verimliliğinin $\% 12$ arttığ 1 belirlenmiştir (Talebnejad ve Sepaskhah 2015).

Dünya kinoa talebinin yaklaşık \%90’1, Peru ve Bolivya tarafından karşılamakta, bu ülkeleri daha küçük ölçekli üretimler ile Kolombiya, Ekvador, Şili ve Arjantin ve Amerika Birleşik Devletleri izlemektedir (FAO 2017). Kinoa bitkisinin anavatanı olan Güney Amerika ülkelerinde, su kaynaklarının sınırlı ve bitkinin kuraklığa dayanımının yüksek olması nedenleriyle, geçmişte kinoanın sulu tarımı bir seçenek olarak değerlendirilmemiş, yapılan çalışmalar da daha çok tuzluluk ve kuraklık stresi koşullarında yetiştiriciliği üzerine odaklanmıştır. Ancak kinoanın besin ögelerinin üstünlüğünün gündeme gelmesi, pazar talebinin artması ve üretiminin yetersiz kalmas1 sonucu kinoanın sulu koşullarda yetiştiriciliği önem kazanmış, bu amaçla son yıllarda projeler yürütülmeye başlanmıştır (Jacobsen 2003; Bhargava ve ark. 2006). Bu nedenle kinoa Kanada, Danimarka, Hollanda, Fransa, İsveç, İtalya, Fas, Çin, Hindistan ve İngiltere dahil birçok ülkede yetiştirilmeye başlanmıştır (Jaikishun ve ark. 2019).

Jacobsen ve ark. (2012), kinoa üretiminin artırılması konusunda Akdeniz bölgesinde büyük bir potansiyel bulunduğunu bildirmiştir. Yazar ve Kaya (2014) ise kinoanın, strese toleransı ve farklı çevrelere uyum özelliği, besin içeriği ve ekonomik değeri sayesinde Türkiye'de marjinal tarım alanları için önerilebilecek alternatif ürün olduğunu ileri sürmüşlerdir.

Kinoanın sulamalı koşullarda üretimine ilişkin çalışmalar görece olarak az sayıda olup daha çok yüksek bölgeleri, farklı iklimsel özellikleri temsil eder niteliktedir. Bu çalışmada, kinoa bitkisinin Akdeniz Bölgesi ikliminde, drenaj tipi lizimetre koşullarında su-verim ilişkileri, bitki su tüketimi (ET) ve farklı gelişme dönemlerindeki bitki katsayılarının $\left(\mathrm{K}_{\mathrm{c}}\right)$ belirlenmesi amaçlanmıştır.

\section{Materyal ve Yöntem}

Araştırma, $30^{\circ} 38^{\prime} 30^{\prime \prime E}$ boylamları ve $36^{\circ} 53^{\prime} 15^{\prime \prime} \mathrm{N}$ enlemleri arasında, denizden 54 m yüksekteki Antalya'da 2017 yılında yürütülmüştür. Bölgede Akdeniz iklimi hüküm sürmekte olup yazlar sıcak ve kurak, kışlar ılık ve yağışlıdır. Antalya'da yıllık ortalama sicaklık $18.7^{\circ} \mathrm{C}$, en soğuk ay $10.0^{\circ} \mathrm{C}$ ile Ocak ve en sicak ay ise $28.4^{\circ} \mathrm{C}$ ile Temmuz ayıdır. Yıllık ortalama bağıl nem $\% 63.2$, ortalama toplam yağış $1085.3 \mathrm{~mm}$ ve ortalama toplam buharlaşma 1826.5 mm'dir (MGM 2020). Çalışmanın yürütüldüğü drenaj tipi lizimetre sistemi, her biri $2 \times 1 \mathrm{~m}$ boyutlu ve $1.8 \mathrm{~m}$ derinliğe sahip, içi ortalama olarak kuru ağırlık esasına göre tarla kapasitesi değeri \%16.7, devamlı solma noktası değeri $\% 9.9$, hacim ağırlı̆̆ $1.5 \mathrm{~g} \mathrm{~cm}^{-3}$ olan kumlu tın bünyeli toprakla doldurulmuş 15 adet beton bölmeden oluşmaktadır. Lizimetre toprakları tuzsuz $(\% 0.031)$, orta derecede alkali $(\mathrm{pH}=8.2)$, çok kireçli (\%23.7) özelliğe sahiptir. Araştırmada Akdeniz koşullarına iyi adapte olmuş Titicaca (Q-52) kinoa çeşidi (Lavini ve ark. 2014) kullanılmıştır. Sulama suyunun elektriksel iletkenliği $0.48 \mathrm{dS} \mathrm{m}^{-1}$ olup sulamada güvenle kullanılabilir niteliktedir (Ayers ve Westcot 1985). İşlenen parsellere ekimden önce, $8 \mathrm{~kg} \mathrm{da}^{-1}$ saf $\mathrm{N}, \mathrm{P}, \mathrm{K}$ olacak şekilde kompoze gübre uygulaması yapılarak tüm gübre bir seferde verilmiştir. Kinoa tohumları, $1.5-2.0 \mathrm{~cm}$ derine, sira aras1 mesafe $50 \mathrm{~cm}$ olacak şekilde (Jacobsen 2003) 15.03.2017 tarihinde (Yazar ve Kaya 2014) elle ekilmiştir. Çıkıştan sonra sıra üzeri mesafe 8-10 $\mathrm{cm}$ olacak şekilde seyreltme yapılarak her bir lizimetre parselinde 34-39 bitki bırakılmıştır. Deneme süresince ot ve zararlılarla mücadele işlemleri sürdürülmüştür.

Araştırma, tesadüf blokları deneme desenine göre 3 tekerrürlü olarak düzenlenmiştir. Araştırmada, tam sulama (TS), sirasıyla TS'nin \%75, 50 ve 25'i kadar su uygulanan kısintıl sulama konuları (KS75, KS50, KS25) ve sulama uygulanmayan (SZ) olmak üzere 5 sulama konusu yer almıştır. Deneme konularının uygulanmasına topraktaki kullanılabilir suyun yaklaşık \%40'1 tüketildiğinde başlanmış, TS konusunda sonraki sulamalar 7 gün ara ile, $90 \mathrm{~cm}$ 'lik profil derinliğindeki eksik su tarla kapasitesine getirilecek biçimde uygulanmıştır (Kaya 2010). KS75, KS50, KS25 konularına ise, tam sulama konusu ile aynı günde, kısıntı oranları dikkate alınarak su uygulanmıştır. Sulamalar damla sulama yöntemiyle 
gerçekleştirilmiş̧ir. Her bitki sırasına bir lateral boru hattı döşenmiş, $0.2 \mathrm{~m}$ aralıklı, $1 \mathrm{~atm}$ işletme basıncında $2 \mathrm{~L} \mathrm{~h}^{-1}$ debili, lateral boruya içten geçik tipte, kendinden basınç düzenleyicili damlatıcılar kullanılmıştır. Gerekli su miktarı hacme dönüştürülerek ölçülü bir şekilde uygulanmış, her lizimetre parselindeki lateral borular ayrı birer vana ile kontrol edilmiştir. Sulamalara kinoanın dane dolum dönemi bitiminde son verilmiştir. Ekimden önceki haftada oluşan toplam 161.9 mm'lik yağış nedeniyle, $0-90 \mathrm{~cm}$ 'lik profildeki toprak nemi tarla kapasitesinde iken ekim yapılmış, ancak çıkış sağlanana kadar tüm konulara eşit miktarda $(2 \mathrm{~mm})$ su uygulanmıştır. Hasat 28.06.2017-01.07.2017 tarihleri arasında yapılmıştır.

Araştırmada toprak su içeriği, $1 \mathrm{~m}$ derinliğe yerleştirilen akses tüpleri aracilığ Devices, Cambridge, UK) kullanılarak haftada üç kez ölçüm yapılmak suretiyle izlenmiş̧ir. Ayrıca ekim ve hasat tarihlerinde toprakta gravimetrik nem belirlemesi yapılmıştır.

Meteorolojik veriler araştırma alanında yer alan otomatik meteoroloji istasyonundan (Metos-PESSL Instruments, Austria) alınmıştır. Bitki su tüketimi miktarı aşağıdaki su dengesi eşitliği ile hesaplanmıştır:

$$
\mathrm{ET}=\mathrm{I}+\mathrm{P}-\mathrm{Dp} \pm \Delta \mathrm{SW}
$$

Eşitlikte; ET, bitki su tüketimini (mm); I, uygulanan toplam sulama suyunu $(\mathrm{mm}) ; \mathrm{P}$, yağış miktarını $(\mathrm{mm}) ; \mathrm{D}_{\mathrm{p}}$, derine sızmayı (mm); $\Delta \mathrm{SW}$, ekim ve hasat arasinda toprak suyu depolamasındaki değişimi $(\mathrm{mm})$ göstermektedir. Derine sızmanın olmadığı kabul edilmiştir. Bitki katsayıları $\left(\mathrm{K}_{\mathrm{c}}\right)$, TS konusundan elde edilen ET ve meteorolojik verilerden hesaplanan kıyas bitki su tüketimi $\left(\mathrm{ET}_{\mathrm{o}}\right)$ değerleri kullanılarak aşağıdaki ilişkiyle hesaplanmıştır (Allen ve ark. 1998):

$$
\mathrm{K}_{\mathrm{c}}=\mathrm{ET} / \mathrm{ET}_{\mathrm{o}}
$$

Çalışmada kıyas bitki su tüketiminin $\left(\mathrm{ET}_{0}\right)$ tahmininde aşağıda verilen, FAO56-Penman Monteith formülü (Allen ve ark. 1998) esas alınmış, hesaplama için Reference Crop Evapotranspiration (REF-ET) bilgisayar yazılımı (Allen 2015) kullanılmıştır.

$$
\mathrm{ET}_{\mathrm{o}}=\frac{0.408 \Delta\left(\mathrm{R}_{\mathrm{n}}-\mathrm{G}\right)+\gamma \frac{900}{\mathrm{~T}+273} \mathrm{u}_{2}\left(\mathrm{e}_{\mathrm{s}}-\mathrm{e}_{\mathrm{a}}\right)}{\Delta+\gamma\left(1+0.34 \mathrm{u}_{2}\right)}
$$

Eşitlikte; $\mathrm{ET}_{\mathrm{o}}$, kıyas bitki su tüketimi $\left(\mathrm{mm} \mathrm{gün}^{-1}\right) ; \Delta$, buhar basınc1 eğrisinin eğimi $\left(\mathrm{kPa}^{\circ} \mathrm{C}^{-1}\right) ; \mathrm{R}_{\mathrm{n}}$, bitki yüzeyindeki net radyasyon $\left(\mathrm{MJ} \mathrm{m}^{-2}\right.$ gün $\left.^{-1}\right) ; \mathrm{G}$, toprak 1S1 akıs1 $\left(\mathrm{MJ} \mathrm{m}^{-2}\right.$ gün $\left.^{-1}\right) ; \gamma$, psikrometrik sabit $\left(\mathrm{kPa}^{\circ} \mathrm{C}^{-1}\right)$; $\mathrm{u}_{2}, 2 \mathrm{~m}$ yükseklikteki günlük ortalama rüzgâr hızı $\left(\mathrm{m} \mathrm{s}^{-1}\right) ; \mathrm{T}, 2 \mathrm{~m}$ yükseklikteki günlük ortalama sicaklık $\left({ }^{\circ} \mathrm{C}\right)$; es, doygun buhar basincı $(\mathrm{kPa})$; ea, gerçek buhar basıncı $(\mathrm{kPa})$ 'dır. $\mathrm{R}_{\mathrm{n}}$, ölçülen solar radyasyon, sıcaklık, bağıl nem ve güneşlenme verilerinden hesaplanarak tahmin edilirken, $G$ ise ihmal edilmiştir.

$\mathrm{Su}$ verimliliği (WP) değerleri aşağıdaki eşitlik (Pereira ve ark. 2012) ile hesaplanmıştır:

$$
\mathrm{WP}=\mathrm{Y} / \mathrm{ET}
$$

Eşitlikte; WP, su verimliliği $\left(\mathrm{kg} \mathrm{m}^{-3}\right)$; Y, verim, $\left(\mathrm{kg} \mathrm{da}^{-1}\right)$; ET, bitki su tüketimi (mm)'dir. Su eksikliğinin bitki verimine etkisinin bir göstergesi olan verim tepki etmeni $\left(\mathrm{ky}_{\mathrm{y}}\right)$ ise aşağıda verilen eşitlik (Stewart ve ark. 1977) ile hesaplanmıştır.

$$
\left(1-\mathrm{Y} / \mathrm{Y}_{\mathrm{m}}\right)=\mathrm{k}_{\mathrm{y}}\left(1-\mathrm{ET} / \mathrm{ET}_{\mathrm{m}}\right)
$$

Eşitlikte; $\mathrm{Y}$, gerçek verim $\left(\mathrm{kg} \mathrm{da}^{-1}\right)$; $\mathrm{Y}_{\mathrm{m}}$, maksimum verim $\left(\mathrm{kg} \mathrm{da}^{-1}\right) ; \mathrm{ky}$, verim tepki etmeni; ET, gerçek bitki su tüketimi $(\mathrm{mm}) \mathrm{ET}_{\mathrm{m}}$, maksimum bitki su tüketimi (mm)'dir.

Bitkinin dane verimi, lizimetre parsellerinde, iki bitki sırasının her iki başından birer bitki kenar etkisi olarak ayrıldıktan sonra hasat edilen bitkilerden $\mathrm{kg} \mathrm{da}^{-1}$ olarak belirlenmiştir. Araştırmada elde edilen verilerin istatistiksel analizleri SAS ${ }^{\circledR}$ University Edition istatistik programı ve ortalama değerlerin karşılaştırmasında LSD testi kullanılmıştır.

\section{Bulgular ve Tartışma}

\subsection{Bitki gelişim dönemleri ve uzunluklart}

Ekim tarihi 15.03.2017 ve hasat tarihi 01.07.2017 olan Titicaca (Q-52) kinoa çeşidinin TS konusunda, farklı gelişim dönemlerinin başlangıç ve bitim tarihleri ile dönem uzunlukları (gün sayıs1) Çizelge 1'de verilmiştir.

Çizelge 1. Kinoanın farklı gelişim dönemlerinin başlangıç ve bitim tarihleri ile dönem uzunlukları.

Table 1. The beginning and end dates and the lengths of the different growing periods of quinoa.

\begin{tabular}{lcc}
\hline $\begin{array}{l}\text { Bitki Gelişim } \\
\text { Dönemleri }\end{array}$ & Tarih Aralı̆̆ı & $\begin{array}{c}\text { Gün } \\
\text { Sayısı }\end{array}$ \\
\hline Başlangıç dönemi & 15 Mart-15 Nisan & 31 \\
Gelişme dönemi & 16 Nisan -21 Mayıs & 36 \\
Mevsim ortası dönem & 22 Mayıs- 05 Haziran & 15 \\
Geç dönem & 06 Haziran -01 Temmuz & 26 \\
\hline
\end{tabular}

Bitki katsayısı $\left(\mathrm{K}_{\mathrm{c}}\right)$ değerleri genel olarak başlangıç (ekim tarihi ile toprak yüzeyini yaklaşık \%10 oranında örttüğü dönem aras1), orta (bitki büyümesinin son bulduğu veya çiçeklenme başlangıcı ile bitkinin tamamen gelişip-olgunlaştı̆̆ dönem arası) ve geç dönem (mevsim ortası döneminin sonu ile hasat arası) olmak üzere üç dönem için belirlenir. Bitki katsayısının çok hızlı bir değişim ve değişkenlik gösterdiği gelişme (\%10 örtü-\%70-80 örtü aras1) dönemi için $\mathrm{K}_{\mathrm{c}}$ değeri ise diğer dönemlerdeki $K_{c}$ değerlerinden yararlanılarak grafiksel yolla bulunur (Allen ve ark. 1998). Çizelge 1'den görüleceği üzere bu çalışmada, kinoa bitkisi için başlangıç dönemi 15 Mart-15 Nisan (31 gün), gelişme dönemi 16 Nisan-21 Mayıs (36 gün), orta dönem 22 Mayıs-05 Haziran (15 gün) ve geç dönem 06 Haziran-01 Temmuz arası (26 gün), toplam büyüme dönemi ise 108 olarak belirlenmiştir. Kinoa bitkisinin büyüme periyodunun uzunluğu toplam radyasyondan ve sıcaklıktan etkilenmektedir. Jacobsen (2003), çeşit özelliklerine ve iklimsel koşullara bağlı olarak kinoa bitkisinin gelişme dönemi uzunluğunu 90-180 gün, Pulvento ve ark. (2012) ise Akdeniz bölgesinde 96-110 gün arasında olduğunu bildirmişlerdir. Jacobsen ve Stolen (1993) ise, 16 Mart'ta ekilip 2 Temmuz'da hasat edilen kinoa bitkisinin toplam 109 gün olan büyüme mevsimindeki evreleri erken vejetatif gelişim (37 gün); tomurcuk oluşumuna kadar olan vejetatif gelişim (25 gün); çiçeklenme (11 gün); dane dolumu (22 gün) ve olgunluk (14 gün) dönemleri olarak belirlemişlerdir. İtalya, Yunanistan, İsveç, Danimarka ve Polonya olmak üzere Avrupa'daki 5 farklı ekolojik koşulda kinoa bitkisinin büyüme dönemleri sirasiyla 116, 106, 140, 134 ve 128 gün olarak saptanmıştır (Gesinski 2008). Bitki büyüme evreleri ve toplam büyüme mevsimi uzunluğuna ilişkin olarak bu çalışmada elde edilen bulguların, anılan literatür bulguları ile uyuşumlu olduğu sonucuna varılabilir. 


\subsection{Sulama suyu uygulamaları}

Konulu sulama uygulamalarına 9 Mayıs tarihinde başlanmış ve daha sonra da, 16 ve 30 Mayıs, 5 ve 12 Haziran günlerinde olmak üzere mevsim boyunca toplam 5 sulama yapılmıştır. TS konusuna toplam $108.2 \mathrm{~mm}, \mathrm{KS} 75, \mathrm{KS} 50, \mathrm{KS} 25$ konularına ise sırasıyla; $81.6,55.1$ ve $28.5 \mathrm{~mm}$ sulama suyu uygulanmıştır. Toprak nemi, sulamalara son verilene kadar TS konusunda tarla kapasitesine yakın bir düzeyde devam etmiştir (Şekil 1). Buradan sulama mevsimi boyunca TS konusunun yağış ve sulamalarla su stresi çekmeyecek düzeyde su aldığı sonucuna ulaşılabilir. Diğer konularda ise topraktaki nem deneme konularına bağlı olarak azalmıştır. Toprak nemi, sulamalar sonlandırıldıktan sonra tüm konularda hızla solma noktası düzeyine ve/veya altına düşmüştür.

Konulara uygulanan sulama suyu, yağış ve topraktan kullanılan nem değerleri dikkate alındığında; TS, KS75, KS50, KS25 ve SZ konularında sirasiyla, 302.0, 274.6, 247.3, 220.2 ve $198.3 \mathrm{~mm}$ su tüketimi gerçekleşmiştir. Mevsim boyunca düşen $103.4 \mathrm{~mm}$ yağıştan tüm araştırma konuları etkilendiğinden bitki su tüketimi değerleri 198.3-302.0 mm gibi dar bir aralıkta değişmiştir. Bu durumda, tam sulama konusundaki su tüketimi dikkate alınarak kinoa bitkisinin Antalya koşullarındaki su tüketiminin $302.0 \mathrm{~mm}$ olduğu söylenebilir (Çizelge 2).

İklimsel koşullara bağlı olarak büyüme mevsimi uzunluklarının bölgeden bölgeye değişmesi nedeniyle kinoa su tüketimine ilişkin dünyanın çeşitli yerlerinde yapılan araştırmalarda elde edilen bulgular farkl11ık gösterebilmektedir. Garcia ve ark. (2003), denizden 4000 m yüksekte, BolivyaPatacamaya-Altiplano bölgesinde kinoanın mevsimlik bitki su tüketimini $450 \mathrm{~mm}$ olarak belirlemişlerdir. Razzaghi ve ark. (2012), nemli Avrupa ikliminde, kinoanın bitki su tüketiminin toprak bünyesine bağlı olarak 194-289 mm arasında bulmuşlardır. Steduto ve ark. (2012), ise stressiz koşullarda,
150-170 günlük normal mevsim uzunluğundaki kinoa ET'sinin $500 \mathrm{~mm}$ civarında olduğunu bildirmișlerdir. Bu çalışmada 108 günlük büyüme periyodunda tam sulanan konuda belirlenen 302.0 mm'lik mevsimlik su tüketimi değerinin yukarıdaki bulgularla benzerlik gösterdiği sonucuna ulaşılabilir.

En düşük WP değeri $\left(0.98 \mathrm{~kg} \mathrm{~m}^{-3}\right)$ TS konusunda, en yüksek WP değeri ise SZ konusunda $\left(1.22 \mathrm{~kg} \mathrm{~m}^{-3}\right)$ elde edilmiş ve uygulanan sulama suyu miktarı azaldıkça WP artmıştır (Çizelge 2). Talebnejad ve Sepaskhah (2015), İran'da sera koşullarında en yüksek WP'nin $0.66 \mathrm{~kg} \mathrm{~m}^{-3}$ olduğunu, Kaya (2010), Akdeniz iklim koşullarında farklı tuzluluk düzeyleri ve farklı sulama stratejileri ile yaptığ $\mathrm{kg} \mathrm{m}^{-3}$ arasında değiştiğini, Geerts ve ark. (2008) Bolivya'da tam sulanan konuda $0.41 \mathrm{~kg} \mathrm{~m}^{-3}$ iken $\% 50$ kisintılı sulama yapılan konuda $0.48 \mathrm{~kg} \mathrm{~m}^{-3}$ olduğunu bildirmişlerdir. Lavini ve ark. (2014) ise, farklı düzeyde tuzlu sularla sulanan konularda WP'nin 0.6-0.8 $\mathrm{kg} \mathrm{m}^{-3}$ arasında değiştiğini saptamışlardır. Görüldüğü üzere WP değerleri su kisitl1lığına, suyun tuzluluğuna bağlı olarak değişebilmekte genellikle su kısıtlılığı arttıkça yükselmektedir.

Çizelge 2'deki oransal verim ve oransal ET değerlerinden doğrusal regresyonu yolu ile elde edilen ilişki denklemi Şekil 2'de verilmiştir. İlişkide, doğrunun eğimi olan verim tepki etmeni $\mathrm{k}_{\mathrm{y}}=0.54$ olarak elde edilmiştir. Garcia ve ark. (2003), Bolivya'da, kinoanın mevsimlik ky değerini 0.67; Kaya (2010), Akdeniz iklim koşullarında 0.59; Talebnejad ve Sepaskhah (2015), İran'da yapılan bir lizimetre çalışmasında 2.21; Sezen ve ark. (2017) ise 1.13 olarak belirlemişlerdir. Kaya (2010) ve Garcia ve ark. (2003) ile uyuşumlu olarak bu çalışmadan elde edilen $\mathrm{k}_{\mathrm{y}}$ değerinin 1'den küçük bir değer olması kinoa bitkisinin kuraklığa dayanımının yüksek olduğunun bir göstergesidir.

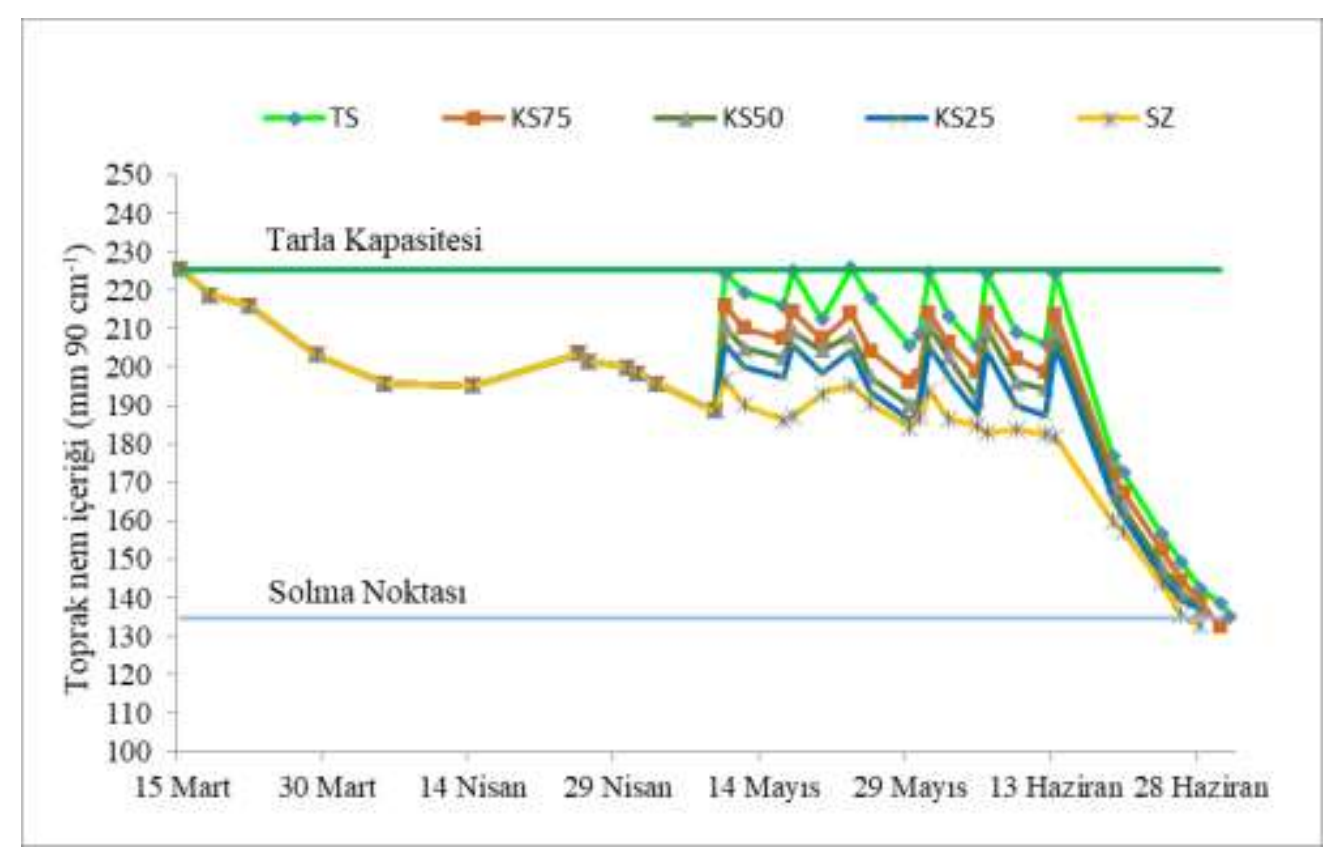

Şekil 1. Deneme süresince sulama konularındaki toprak nem içeriğinin değişimi.

Figure 1. Soil water content change in irrigation treatments. 
Çizelge 2. Bitki su tüketimi (ET) bileşenleri ( $\mathrm{I}=$ sulama, $\mathrm{P}=$ yağış, $\Delta \mathrm{SW}=$ topraktan kullanılan su), elde edilen verim (Y), su verimliliği (WP), oransal verim ve oransal ET değerleri.

Table 2. Components of evapotranspiration ( $E T)$ (I= irrigation, $P=$ precipitation, $\Delta S W=$ water use from soil), yield $(\mathrm{Y})$, water productivity $(\mathrm{WP})$, relative yield and relative ET.

\begin{tabular}{|c|c|c|c|c|c|c|c|c|c|}
\hline $\begin{array}{l}\text { Sulama } \\
\text { Konusu }\end{array}$ & $\begin{array}{c}\text { Çıkış suyu } \\
(\mathrm{mm})\end{array}$ & $\begin{array}{c}\mathrm{I} \\
(\mathrm{mm}) \\
\end{array}$ & $\begin{array}{c}\mathrm{P} \\
(\mathrm{mm}) \\
\end{array}$ & $\begin{array}{l}\Delta \mathrm{SW} \\
(\mathrm{mm})\end{array}$ & $\begin{array}{c}\text { ET } \\
(\mathrm{mm})\end{array}$ & $\begin{array}{c}\mathrm{Y} \\
\left(\mathrm{kg} \mathrm{da}^{-1}\right)\end{array}$ & $\begin{array}{c}\text { WP } \\
\left(\mathrm{kg} \mathrm{m}^{-3}\right)\end{array}$ & $\begin{array}{c}\text { Oransal verim } \\
(\%)\end{array}$ & $\begin{array}{l}\text { Oransal } \\
\text { ET (\%) }\end{array}$ \\
\hline TS & 2.0 & 106.2 & 103.4 & 90.4 & 302.0 & 295.2 & 0.98 & 1.00 & 1.00 \\
\hline KS75 & 2.0 & 79.6 & 103.4 & 89.6 & 274.6 & 284.2 & 1.03 & 0.96 & 0.90 \\
\hline KS50 & 2.0 & 53.1 & 103.4 & 88.8 & 247.3 & 273.6 & 1.10 & 0.93 & 0.82 \\
\hline KS25 & 2.0 & 26.5 & 103.4 & 88.3 & 220.2 & 246.5 & 1.11 & 0.83 & 0.73 \\
\hline SZ & 2.0 & - & 103.4 & 92.9 & 198.3 & 243.0 & 1.22 & 0.82 & 0.66 \\
\hline
\end{tabular}

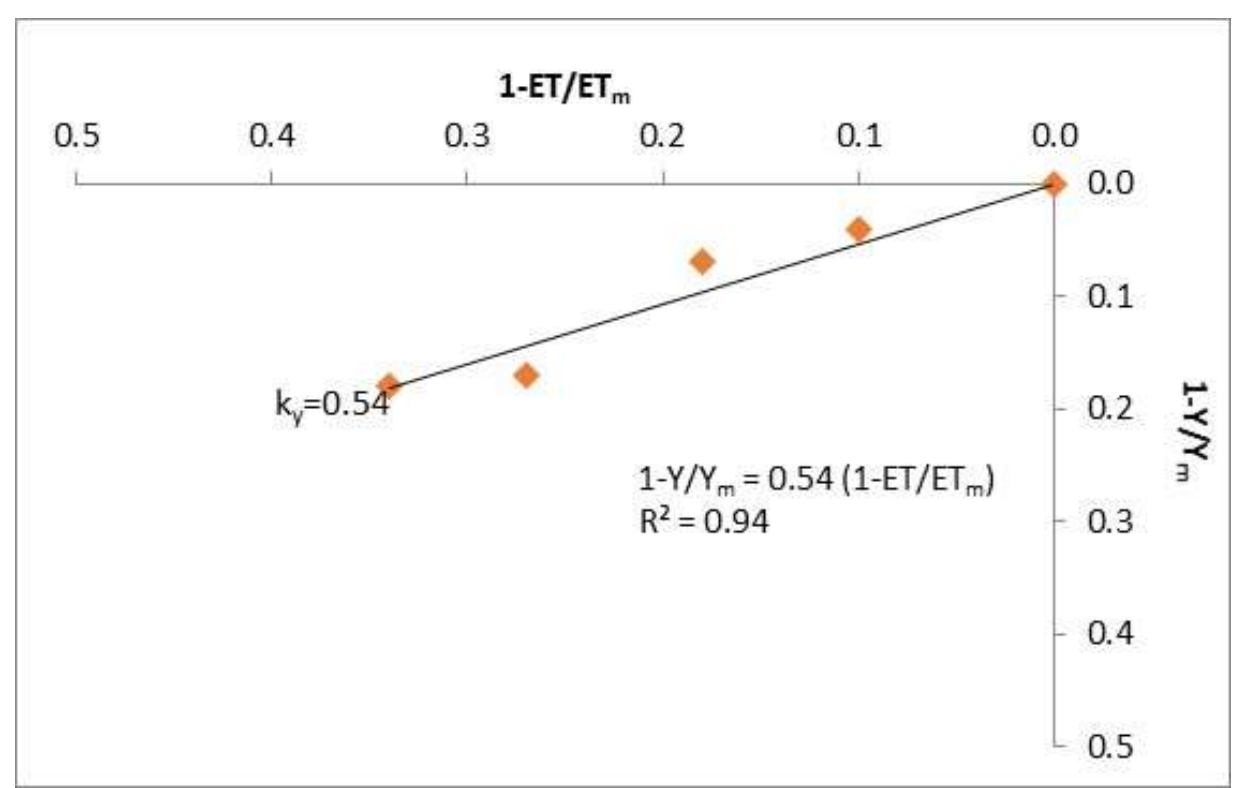

Şekil 2. Toplam büyüme mevsiminde kinoa bitkisi için ET açığı ve oransal verim azalması ilişkisi.

Figure 2. Relation of relative ET deficit and relative yield decrease in growing season of quinoa.

Tam sulama (TS) konusundaki yığışımlı ET değerleri Şekil 3'de, FAO-Penman Monteith Yönteminden yararlanılarak günlük $\mathrm{ET}_{\mathrm{o}}$ '1n hesaplanması için REF-ET bilgisayar yazılımında kullanılan iklimsel veriler, hesaplanan günlük $\mathrm{ET}_{\mathrm{o}}$ değerleri ve ayrıca yağış değerlerinin dağılımı Şekil 4'de gösterilmiştir.

Kinoa bitkisinin gelişme mevsimi süresince REF-ET bilgisayar yazılımı ile hesaplanan günlük kıyas bitki su tüketimi $\left(\mathrm{ET}_{\mathrm{o}}\right)$ değerleri 1.9-8.7 $\mathrm{mm}$ gün $^{-1}$ arasında değişim göstermiştir (Şekil 4). Kinoa bitkisinin başlangıç, orta ve geç gelişme dönemleri için Şekil 3'den elde edilen ET ve Şekil 4'deki verilerden hesaplanan $\mathrm{ET}_{\mathrm{o}}$ değerleri kullanılarak belirlenen bitki katsayıları $\left(\mathrm{K}_{\mathrm{c}}\right)$ değerleri Çizelge 3’te verilmiştir.

Çizelge 3. Kinoa bitkisinin başlangıç, orta ve geç gelişim dönemleri için belirlenen bitki katsayıları $\left(\mathrm{K}_{\mathrm{c}}\right)$.

Table 3. Crop coefficients $\left(\mathrm{K}_{\mathrm{c}}\right)$ of quinoa for the initial, mid-season and late-season stages.

\begin{tabular}{cccc}
\hline Dönemler & $\begin{array}{c}\text { Kinoa Bitki Su } \\
\text { Tüketimi } \\
(\mathrm{ET}, \mathrm{mm})\end{array}$ & $\begin{array}{c}\text { Kıyas Bitki Su } \\
\text { Tüketimi } \\
\left(\mathrm{ET}_{\mathrm{o}}, \mathrm{mm}\right)\end{array}$ & $\begin{array}{c}\text { Bitki Katsayısı } \\
\left(\mathrm{K}_{\mathrm{c}}\right)\end{array}$ \\
\hline Başlangıç & 139.9 & 259.9 & 0.54 \\
Orta & 83.6 & 73.7 & 1.13 \\
Geç & 114.0 & 150.3 & 0.76 \\
\hline
\end{tabular}

Başlangıç döneminde bitki örtüsü tam gelişmediği için bitki su tüketiminin düşük olması nedeniyle $K_{c}$ değeri en düşük (0.54) seviyededir. Bitkinin maksimum bitki örtüsüne (çiçeklenme) ulaştığı mevsim ortası dönemde $\mathrm{K}_{\mathrm{c}}$ değeri de en yüksek değerine (1.13) ulaşmaktadır. Verim oluşumu ve olgunlaşmayı kapsayan geç dönemde ise yaprakların sararıp dökülmesiyle, bitki su tüketiminde azalma ve $\mathrm{K}_{\mathrm{c}}$ 'de düşme (0.76) meydana gelmektedir (Çizelege 3). Garcia ve ark. (2003), Bolivya'nın Altiplano bölgesinde, Razzaghi ve ark. (2012) ise Danimarka'da drenaj tipi lizimetrelerde, kinoanın $K_{c}$ değerlerini, başlangıç mevsim ortası ve olgunlaşma dönemleri için sirasiyla $0.50,1.00,0.70$ ve $1.05,1.22,1.0$ olarak saptamışlardır. Talebnejad ve Sepaskhah (2015), İran koşullarında Titicaca kinoa çeşidinde, $\mathrm{K}_{\mathrm{c}}$ değerlerini başlangıç, mevsim ortası ve mevsim sonu dönemleri için sırasıyla $0.58,1.2$ ve 0.8; Pulvento ve ark. (2012) $0.7,1.15$ ve 0.4 olarak bildirmişlerdir. Geerts ve ark. (2008) ise kinoa için $\mathrm{K}_{\mathrm{c}}$ değerlerini başlangıç dönemi için 0.14-1.0 arası, mevsim ortası ve olgunlaşma dönemleri için sırasıyla 1.0 ve 0.6 olarak belirlemişlerdir. $\mathrm{Bu}$ çalışmadan elde edilen $\mathrm{K}_{\mathrm{c}}$ değerleri literatürdeki değişim sınırları içinde olup özellikle aynı çeşit kinoa ile İran'da yürütülen çalışmadan (Talebnejad ve Sepaskhah 2015) elde edilen değerler ile benzerdir. 


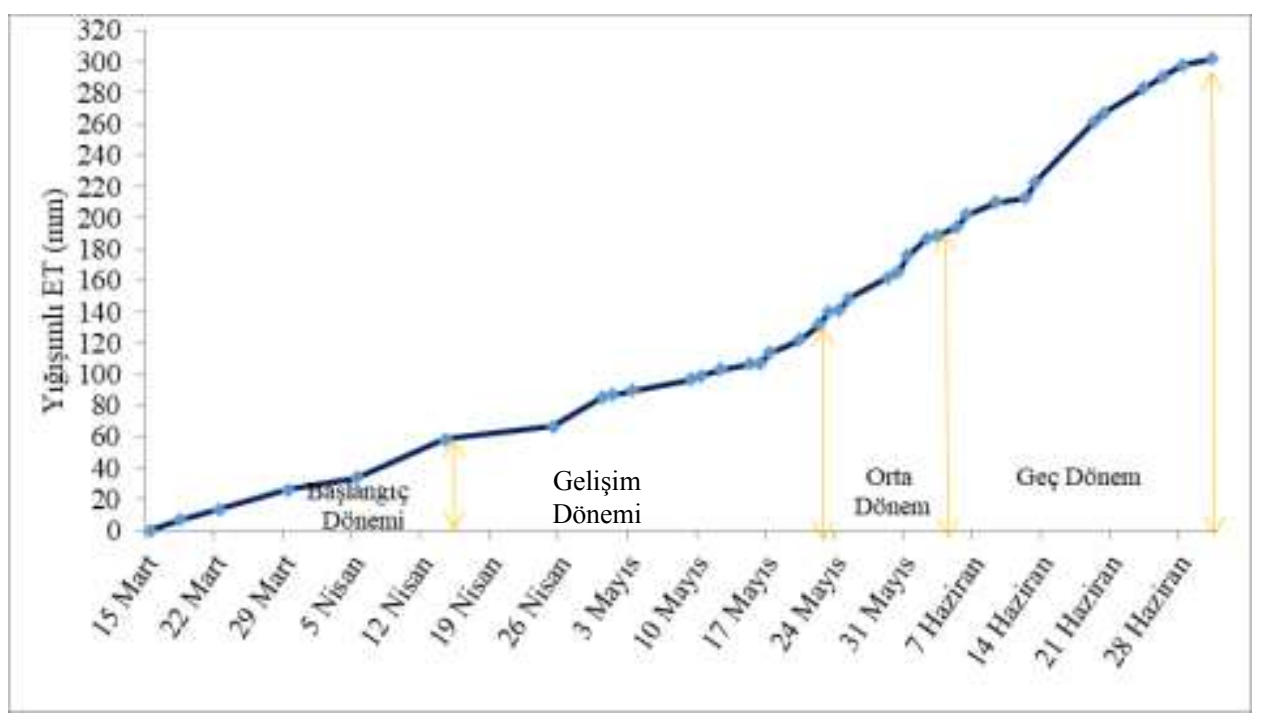

Şekil 3. Kinoa bitkisi için tam sulama konusunda (TS) yığışımlı bitki su tüketimi (ET) grafiği.

Figure 3. Cumulative evapotranspiration (ET) of quinoa in full irrigated (TS) treatment.

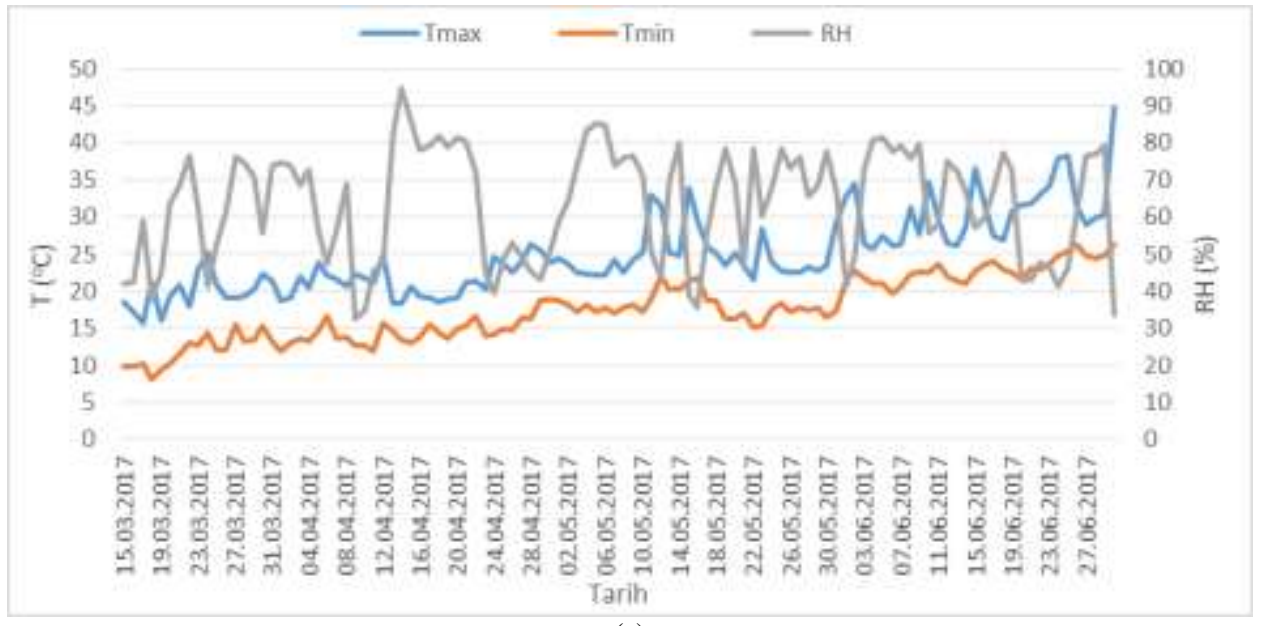

(a)

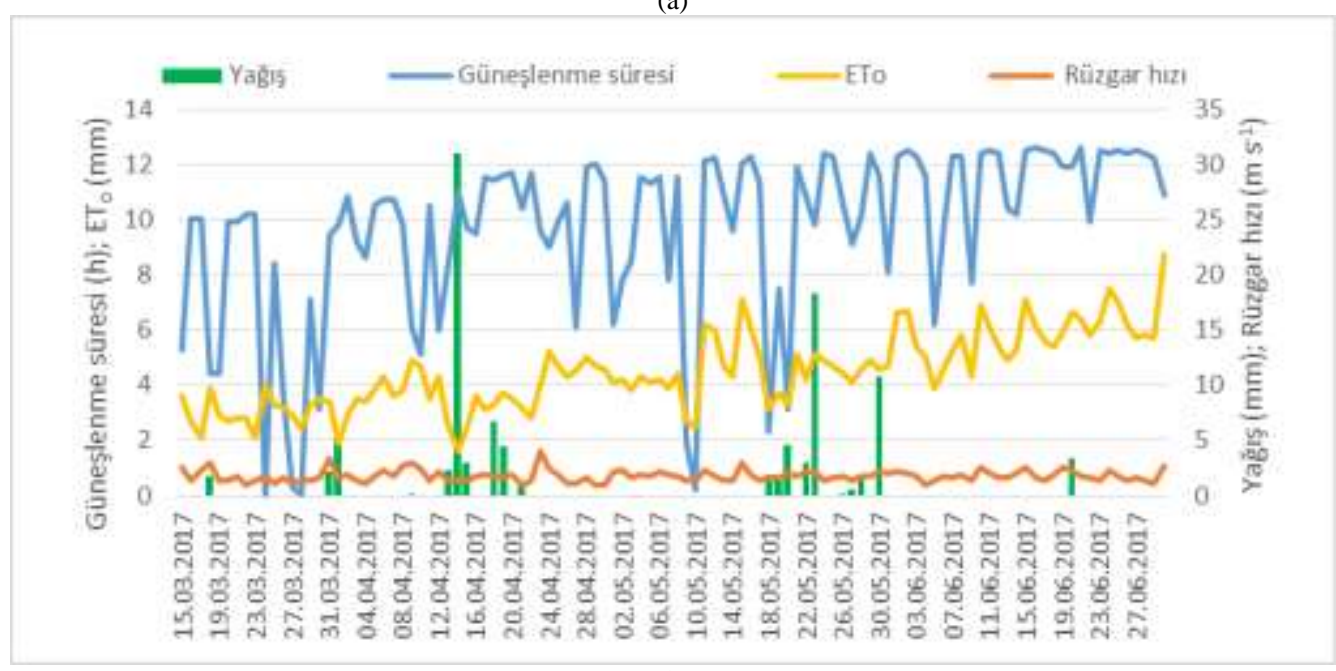

(b)

Şekil 4. Kıyas bitki su tüketimi hesaplamasında kullanılan (a) maksimum sıcaklık $\left(\mathrm{T}_{\max },{ }^{\circ} \mathrm{C}\right)$, minimum sıcaklık $\left(\mathrm{T}_{\min },{ }^{\circ} \mathrm{C}\right)$, bağıl nem (RH, \%), (b) güneşlenme süresi $(\mathrm{h})$, rüzgar hızı $\left(\mathrm{m} \mathrm{s}^{-1}\right)$, REF-ET bilgisayar yazılımı ile hesaplanan günlük kıyas bitki su tüketimi $\left(\mathrm{ET}_{\mathrm{o}}\right)$ değerleri ile yağış $(\mathrm{mm})$ değerlerinin dağılımı.

Figure 4. Change in (a) maximum $\left(T_{\max },{ }^{\circ} \mathrm{C}\right)$, minimum temperature $\left(\mathrm{T}_{\min },{ }^{\circ} \mathrm{C}\right)$, relative humidity $(\mathrm{RH}, \%)$, (b) sunshine hours $(\mathrm{h})$, wind speed $\left(\mathrm{m} \mathrm{s} \mathrm{s}^{-1}\right)$, reference crop evapotranspiration $(\mathrm{mm})$ calculated by REF-ET software and precipitation $(\mathrm{mm})$. 


\section{Sonuçlar}

Akdeniz Bölgesinde, yürütülen bu çalışmada, kinoanın su tüketim değerleri sulama konularına göre 198.3-302.0 mm, WP $0.98-1.22 \mathrm{~kg} \mathrm{~m}^{-3}$, verim değerleri $295.2-243.0 \mathrm{~kg} \mathrm{da}^{-1}$ arasında değişmiş, kinoa bitkisinde su kısıntısı arttıkça verimde istatistiksel olarak önemli azalma olduğu, ayrıca tam sulamanın $\% 25$ 'i düzeyinde kisintılı sulama yapmanın kinoa dane veriminde istatistiksel açıdan fark yaratmadığı saptanmıştır.

Sonuç olarak, kinoanın başlangıç, orta ve geç gelişme dönemleri için sırasıyla $0.54,1.13,0.76$ olarak belirlenen $\mathrm{K}_{\mathrm{c}}$ değerlerinin Akdeniz Bölgesinde kinoanın sulama suyu gereksinimi hesaplamalarında, mevsimlik $\mathrm{k}_{\mathrm{y}}(0.54)$ değerininse su tasarrufu amaçlı sulama planlamalarında kriter olarak kullanılması, ele alınan deneme konularına dayanılarak kısıntılı sulama koşullarında tam sulamanın $\% 25$ 'i düzeyinde kısıntı yapılması önerilebilir. Ayrıca, kinoaya son yıllarda artan ilgi nedeniyle sulu koşullarda kinoa tarımına ilişkin benzeri çalışmaların artırılması önerilebilir.

\section{Teşekkür}

$\mathrm{Bu}$ çalışma Akdeniz Üniversitesi Bilimsel Araştırma Projeleri Koordinasyon Birimi tarafindan (Proje No. FYL-20172365) desteklenmiştir ve söz konusu projeden üretilen 1 . yayındır.

\section{Kaynaklar}

Allen RG, Pereira LS, Raes D, Smith M (1998) Crop evapotranspiration guidelines for computing crop water requirements. FAO İrrigation and Drainage, Paper 56, Rome.

Allen RG (2015) REF-ET: Reference evapotranspiration calculation software for FAO and ASCE standardized equations. User manuel. University of Idaho, Idaho.

Ayers AS, Westcot DW (1985) Water quality for agriculture. FAO İrigation and Drainage, Paper 20, Rome.

Bhargava A, Shukla S, Ohri D (2006) Chenopodium quinoa-An Indian perspective, Industrial Crops and Products 23:73-87.

FAO (2017) FAOSTAT. World quinoa production statistics. FAO, Rome. http://www.fao.org/faostat/en/\#data/QC. Erişim 27 Haziran 2018.

Flynn RO (1990) Growth characteristics of quinoa and yield response to increase soil water deficit. MS Thesis, Colorado State Univ. Fort Collins, U.S.A.

Garcia M, Raes D, Jacobsen SE (2003) Evapotranspiration analysis and irrigation requirements of quinoa (Chenopodium quinoa Willd.) in the bolivian highlands. Agricultural Water Management 60: 119134.

Geerts S, Raes D, Garcia M, Vacher J, Mamani R, Mendoza J, Huanca R, Morales B, Miranda R, Cusicanqui J, Taboada C (2008) Introducing deficit irrigation to stabilize yields of quinoa (Chenopodium quinoa Willd.). European Journal of Agronomy 28: 427-436.

Gesinski K (2008) Evaluation of the development and yielding potential of Chenopodium quinoa Willd. under the climatic conditions of Europe, Part One: Accomodation of Chenopodium quinoa (Willd.) to different conditions. Acta Agrobotanica 61(1):179-184.

Jacobsen SE, Stolen O (1993) Quinoa-morphology and phenology and prospects for its production as a new crop in Europe. European Journal of Agronomy 2: 19-29.

Jacobsen SE (2003) The worldwide potential for quinoa (Chenopodium quinoa Willd.). Food Reviews International 19: 167-177.
Jacobsen SE, Mujica A, Jensen CR (2006) The resistance of quinoa (chenopodium quinoa willd.) to adverse abiotic factors. Food Reviews International 19: 99-109.

Jacobsen SE, Monteros LJ, Corcuera LA, Bravo JL, Christiansen AM (2007) Frost resistance mechanisms in quinoa (Chenopodium quinoa Willd.). European Journal of Agronomy 26: 471-475.

Jacobsen SE, Jensen CR, Liu F (2012) Improving crop production in the arid Mediterranean climate. Field Crops Research 128: 34-47.

Jaikishun S, Li W, Yang Z, Song S (2019) Quinoa: In perspective of global challenges. Agronomy 9: 1-16.

Kaya Ç (2010) Akdeniz bölgesinde damla sistemiyle tatlı ve tuzlu su kullanılarak uygulanan farklı sulama stratejilerinin quinoa bitkisinin verimiyle toprakta tuz birikimine etkileri ve saltmed modelinin test edilmesi. Çukurova Üniversitesi Fen Bilimleri Enstitüsü Tarımsal Yapılar ve Sulama Anabilim Dalı Yüksek Lisans Tezi, Adana.

Koziol MJ (1992) Chemical composition and nutritional evaluation of quinoa (Chenopodium quinoa Willd.). Journal of Food Composition and Analysis 5: 35-68.

Lavini A, Pulvento C, D'andria R, Riccardi M, Choukr-Allah R, Belhabib O, Yazar, A, Ince Kaya Ç, Sezen SM, Qadir M, Jacobsen SE (2014) Quinoa's potential in the Mediterranean region. Journal of Agronomy and Crop Science 200(5): 344-360.

MGM (2020) T.C Tarım ve Orman Bakanlı̆̆ı, Meteoroloji Genel Müdürlüğü, https://www.mgm.gov.tr/veridegerlendirme/il-veilceler-istatistik.aspx?m=ANTALYA. Erişim 02 Mayıs 2020.

Pereira LS, Cordery I, Lacovides L (2012) Improved indicators of water use performance and productivity for sustainable water conservation and saving. Agricultural Water Management 108: 3951.

Pulvento C, Riccardi M, Lavini A, Iafelice G, Andrea R (2012) Yield and quality characteristics of quinoa grown in open field under different saline and unsaline irrigation regimes. Journal of Agronomy and Crop Science 198: 254-263.

Razzaghi F, Plauborg F, Jacobsen SE, Jensen CR, Andersen MA (2012) Effect of nitrogen and water availability of three soil types on yield, radiation use efficiency and evapotranspiration in field-grown quinoa. Agricultural Water Management. 109: 20-29.

Schlick G, Bubenheim DL (1996) Quinoa: Candidate crop for NASA's controlled ecological life support systems. p. 632-640. In: J. Janick (ed.), Progress in new crops. ASHS Press, Arlington, VA. https://www.hort.purdue.edu/newcrop/proceedings1996 /V3632.html.

Sezen SM, Yazar A, Özer S, Akça H, Yıldız M, Günaçtı H, BozkurtÇolak Y, Madanoğlu O (2017) Çizgi kaynaklı yağmurlama sulama sistemi ile uygulanan drenaj ve kanal suyunun quinoa bitkisinin verim, verim bileşenleri ile su kullanım randımanı üzerine etkileri. Proje Sonuç Raporu, Alata Bahçe Kültürleri Araştırma Enstitüsü Mersin.

Steduto P, Hsiao CT, Ferers E, Raes D (2012) Crop yield response to water. FAO İrrigation and Drainage, Paper 66, Rome.

Stewart JI, Cuenca RH, Pruitt WO, Hagan RM, Tosso J (1977) Determination and utilization of water production functions for principal California crops. W-67 CA Contributing Project Report, University of California, Davis, USA.

Talebnejad R, Sepaskhah AR (2015) Effect of different saline ground water depths and irrigation water salinities on yield and water use of quinoa in lysimeter. Agricultural Water Management 148: 177188.

Yazar A, Kaya Çİ (2014) A New Crop for Salt Affected and Dry Agricultural Areas of Turkey: Quinoa (Chenopodium quinoa Willd.). Turkish Journal of Agricultural and Natural Sciences Special Issue 2: 1440-1446. 